\title{
Performance Evaluation Model according to Performance Improvement and Satisfaction of the Staff in the Individual Sports Federations and Federations with Historical Aspect
}

\author{
${ }^{1}$ Maedeh Kolbadinejad, ${ }^{1}$ Farideh Ashraf Ganjouei* , ${ }^{1}$ Zahra Haji Anzehaei \\ ${ }^{1}$ Department of Sport Management, Faculty of Sports Science, Central Tehran Branch, Islamic Azad University, Tehran, Iran.
}

\begin{abstract}
Background. Considering the importance of the role of performance appraisal in organizations, we conclude that performance evaluation has played a major role in achieving human resource productivity. On the other hand, due to the importance of human resources and the role played by the organization, attention to the attitudes and behaviors of this valuable factor is very important. Objectives. This study aimed to present a performance evaluation model according to performance improvement and satisfaction of staff of individual sports federations and those that have historical aspect. Methods. 152 staffs of individual sports federations and those that have a historical aspect of Iran from totaling 260 staffs were participated in this study. To assess organizational performance, improvement of organizational performance (Achieve) of Hersey and Goldsmith and JDI standard questionnaire were used to measure job satisfaction. Structural equations were used for fitting the model to the data. Results. The results showed a significant relationship between job satisfaction and its components with improvement of performance and its components. Conclusion. According to the results, factor load indicated a positive and significant relationship between satisfaction and performance which shows the best fit of a suitable model.
\end{abstract}

KEY WORDS: Job Performance, Job Satisfaction, Performance Evaluation.

\section{INTRODUCTION}

Improvement of job performance is a central issue in present-day organizations. Productivity through job performance stands as a widely researched domain in literature of organizational behavior and human resource development (1). in the field of organizational psychology, individual job performance is a central concept, \&Despite its fundamental importance in most decisions involving human resources, there is still no comprehensive theory of job performance (2).

The advancement and success of organizations in world markets depends on having efficient and appropriate manpower. A manpower with a desirable performance while being happy and interested in a job that can be expected of creativity and innovation in the job (3).As a matter of fact, businesses nowadays under modern management perspective duly takes into consideration the employees' personal needs, wants and desires to be a very good indicators for achieving job satisfaction .Ideally, logic commands that when an employee is satisfied with his job, that will make him happy and when he is happy he will likely become a successful employee (4).

*. Corresponding Author:

Farideh Ashraf Ganjouei

E-mail: ganjouei@yahoo.com 
Job Satisfaction creates a positive affective status in the organization, which is associated with the emergence of social and participatory behaviors. In other words, the prevailing atmosphere of job satisfaction increases the sense of attachment and interest in the organization in individuals (5). Rahman and others (2017) stated that Organizations could play an important role in employee's job satisfaction and productivity by paying close attention to the energy and time of employees' work environments. Human interaction and interpersonal communication with colleagues and supervisors are the main keys of employee job satisfaction (6). Jalili Shishvan et al (2018) in their research pointed out that School principals should have a friendly and intimate relationship with physical education teachers and not communicate with them vaguely. The existence of a serious and orderly environment in the school increases the work-life balance and job satisfaction of physical education teachers. Considering the systems of clear rewards and justice, considering the recreational and recreational facilities, consideration of the material and economic needs of physical education teachers is recommended to improve their performance and satisfaction (7). According to Gula et al. (2018), a direct relationship exist between P-E fit and job performance. Job satisfaction partially mediates the relationships between P-E fit and job performance (8). Raziq and Maulabakhsh (2015) in their research pointed out that organizations should meet the needs of their employees by providing good working conditions, in order to increase their efficiency, productivity and commitment. In a work environment where employees are a part of the overall decision-making process, flexible working conditions, low workload, teamwork approach and supportive management have a positive impact on staff's performance, consequently resulting in a high level of employee job satisfaction(9). According to Suttikun et al. (2018), it is important for spa employers to be aware of the needs of their employees and to create opportunities for employees to successfully meet those needs in order to increase job satisfaction and work performance (10). Organizations are basically created to achieve goals, and the success rate in achieving these goals is directly related to the way employees perform, thus, the evaluation of personnel performance in human resource management has a special place. The results of the correct assessments is the selection of suitable people with the right skills in the right place at the right time, otherwise no decision can be made on the payments and relative conditions in the organization (11). What is important is to note that in each evaluation system, an evaluation system appropriate to the organization needs to be developed (12). Since human resources are confronted with personal and professional problems inside and outside the organization, paying attention to the motivational factors and increasing the level of satisfaction in employees is one of the most important issues to be considered by managers of the organizations (11). Today, sports organizations are also subject to continuous changes \&Despite the constant efforts to design optimal and effective systems for assessing staff, evidence suggests that in general, organization officials are not satisfied with methods and systems for evaluating staff (13). The main reasons for this dissatisfaction are a variety of factors, which includes the complexity of the evaluation process and the existence of deficiencies in the comprehensive evaluation system (14). According to Mrhalek \& Kajanova (2017), dissatisfaction was shown for career development and evaluation of their work (15). Huselid (1995) claims that the performance evaluation system is the most important step that can improve knowledge, skills and capabilities of the current and future staff of an organization, increase staff's incentive, reduce workload and increase labor longevity (16). While Chandraand Frank (2004), from the findings of a US medical center study, states that the staffs were reluctant to evaluate performance because they feel that the evaluation is quite ceremonial and does not have a positive outcome for them (17). Javaherizadeh (2011) states that the impossibility of evaluating systems, the inability of evaluators to properly and fairly evaluate, and the inappropriateness and conformity of evaluation systems with the realities are among the problems responsible for the ineffectiveness of most evaluation systems (18). Ansari et al. (2011) stated that: Due to the lack of familiarity of some managers with the characteristics of evaluators and the desirability of evaluating, an evaluation model should be 
presented at the sports federations. The diversity and complexity of sports federations require that each discipline be presented in a specific model in order to assess organizational performance (19). Unfortunately, so far, there has not been much research on military formulation for assessing the performance of sports organizations, especially federations, and sometimes based on a general view of the functioning of federations, given their success or failure on sports grounds and in competitions such as the Olympic Games, Asian Games and World Cups. This kind of view at the performance of the federations has led to incorrect judgments about the performance appraisal of these units and made attention to be given to other aspects of performance, such as the success of sport development, with regard to existing resources, the level of productivity and efficiency (20).

The gap between current researches and pervious researches is that on one hand, in the majority of studies conducted, the great importance of the evaluation system and its role on improving the staff's performance and satisfaction has been emphasized, and on the other hand, nowadays in majority of researches, there is the gap of the ineffectiveness of such an assessment, its ceremonial nature and the staffs are disregarded in the organizations (in particular sports federations). The researcher's effort is to design a comprehensive and effective organizational performance evaluation system that can provide a framework for analyzing the strengths and weaknesses of the organization in terms of the staff's performance and providing a platform for improving organizational performance and job satisfaction.

\section{MATERIALS AND METHODS}

Research Method. This research method is a descriptive-survey. The collection of data was done through a field study.

Participants. The statistical population of this study was the individual sport federation staff (with the exception of the chairman and vice chairman) and federations that have a historical aspect and are less well-considered, and consisted of 260 people. According to the Morgan table and a cluster sampling, 152 people from fourteen Federation including equitation, golf, polo, archery, boxing, table tennis, tennis, life-saving and diving, gymnastics, bowling and billiards, and Bulls, squash, fencing, skating and track and field, formed the sample.

Data collection tool. Achieve Hersey and Gold Smith questionnaires were used to identify the factors affecting employees' performance and JDI standard questionnaire was used for assessing job satisfaction among the staff. The performance questionnaire contained 42 questions and seven components which included ability (4 items), clarity (7 items), help (5 items), incentive (6 items), assessment (9 items), validity (6 items), and environment (5 items). The Job Satisfaction Questionnaire also contained 25 questions and evaluated five components which included: payment (4 items), promotion and progress (5 items), supervisor (5 items), occupation (5 items) and colleagues ( 5 items).

To assess validity, experts of sport management were used. Also, exploratory and confirmatory factor analysis was used for each questionnaire. Cronbach's alpha was used to investigate the reliability of the research tool, which was conducted in a guideline study based on a sample of 20 , and all of the values were above 0.7 , so the questionnaire had a desirable reliability.

Statistical Analysis. Descriptive and inferential method was used. In the descriptive section, by drawing graphs and reporting frequency and frequency percentages as well as the indexes of central tendency and dispersion, the population of the study, the variables and questions of the questionnaire were addressed. In the inferential part, firstly, exploratory and confirmatory factor analysis for the two questionnaires used in the research was considered. In order to investigate the differences between different federations in terms of improving performance and job satisfaction, nonparametric method of Kruskal-Wallis test was used, due to the rejection of the assumption of normality of the data at level of 0.05 . To measure the level of performance and satisfaction, onesample Wilcoxon test was used and a median response of 3 was considered for each evaluation variable. In order to fit the model into the data, structural equations were used.

Conceptual Model. The model in this research is presented in the following steps: The first step involves designing the original research 
pattern by integrating the two Achive and JDI patterns and extracting appropriate indicators for evaluating the performance of employees using this integrated model. In the next step, using standard questionnaires for two models, the groups are self-evaluated regarding the desired indicators. Finally, the employees' evaluation model is statistically validated based on performance patterns and job satisfaction. The conceptual model of research is as follows:

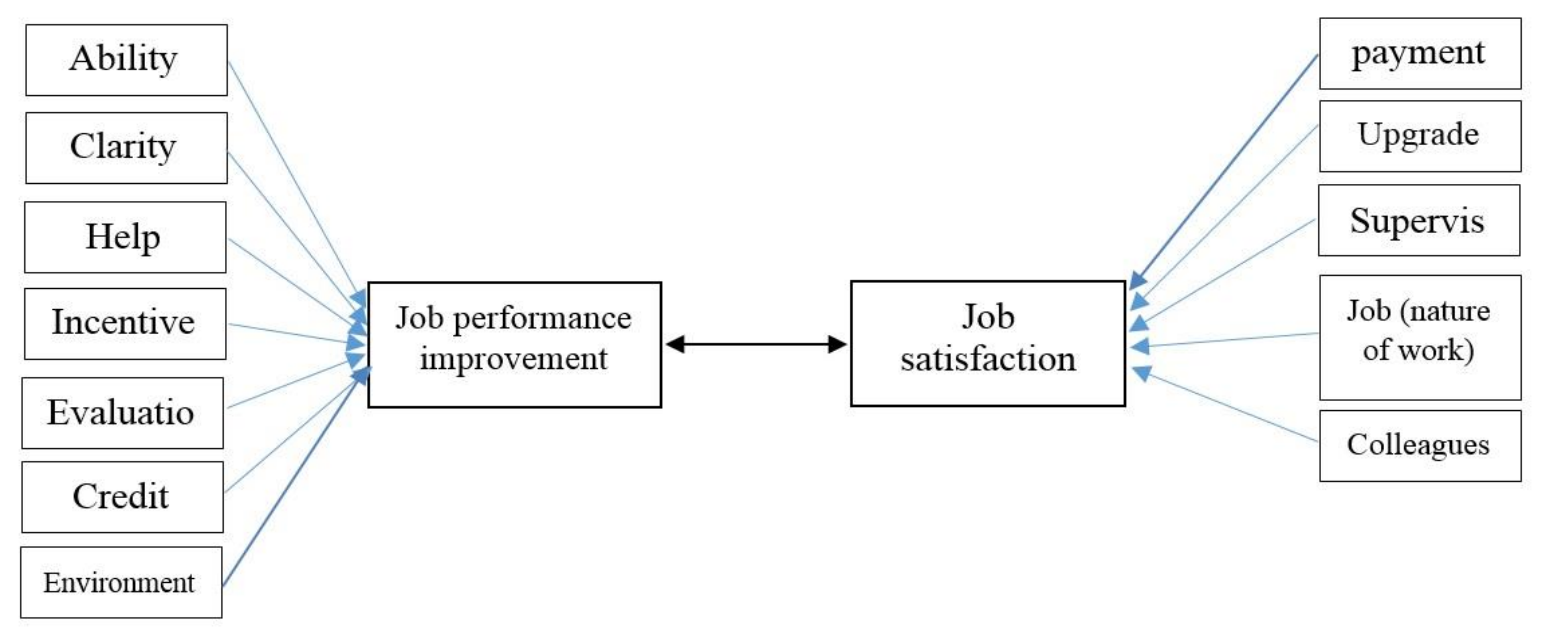

Figure 1. The conceptual model of research.

\section{RESULTS}

Hypothesis 1: The status of improvement of performance and its components is desirable in sports federations' staff. According to the results of Table 1, Wilcoxon test was used to examine this hypothesis.

Table 1. Results of the test hypothesis nh

\begin{tabular}{cccc}
\hline Variable & Mean & Statistic of Wilcoxon & p \\
\hline Ability & 3.25 & 4252.0 & 0.001 \\
Clarity & 3.14 & 4912.0 & 0.013 \\
help & 3.20 & 4523.0 & 0.016 \\
Encouragement & 3.25 & 5816.0 & 0.000 \\
Evaluation & 3.17 & 5144.0 & 0.005 \\
Credit & 3.08 & 4314.0 & 0.103 \\
Environment & 3.00 & 3331.0 & 0.440 \\
Performance improvements & 3.16 & 5649.5 & 0.001 \\
\hline
\end{tabular}

The results showed that at the error level of 0.05 , the performance improvement and all its components were in a favorable situation except for the components of credit and environment. Since the probability value of the Wilcoxon test for the relevant variables was less than 0.05 , therefore, the zero hypothesis indicating relative condition and poor performance was rejected and the researcher hypothesis indicating desired condition in the performance improvement was confirmed.

Hypothesis 2: The status of job satisfaction and its components is desirable in staff of sports federations. According to the results of Table 2, Wilcoxon test was used to examine the above hypothesis. 
Table 2. Results of the second hypothesis test

\begin{tabular}{cccc}
\hline Variable & mean & Statistic of Wilcoxon & Probability value \\
\hline payment & 2.13 & 660.0 & 0.999 \\
promotion and progress & 2.60 & 1668.5 & 0.999 \\
supervisor & 3.10 & 4319.5 & 0.219 \\
nature of work & 3.30 & 558.5 & 0.001 \\
colleagues & 3.50 & 5904.0 & 0.000 \\
job satisfaction & 2.96 & 4126.0 & 0.725 \\
\hline
\end{tabular}

According to the results, at the error level of 0.05 , the job satisfaction status in the general condition was lower than the median level of 3 and the Wilcoxon test was not meaningful; researcher hypothesis were rejected and the zero hypothesis was confirmed.

Also, in the payment components, the promotion and progress of dissatisfaction was observed and in the component of the supervisor, although the median was more than 3 , but it was not statistically significant as the probability value obtained was greater than $0 / 05$; so the researcher hypothesis was not confirmed. However, in the components of the nature of work and colleagues, the level of satisfaction was more than the mean value of 3 , and it can be accepted that the employees were only satisfied with the nature of these two components.

Hypothesis 3: A relationship exists between job satisfaction and its components and improving performance and its components. According to the results of Table 3, Spearman Correlation test was used to examine the above hypothesis.

Table 3. Relation between satisfaction and its components with performance and its components

\begin{tabular}{|c|c|c|c|c|c|c|c|c|c|}
\hline$\frac{\frac{0}{0}}{\frac{\pi}{\pi}}$ & 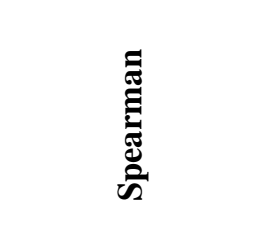 & 莬 & 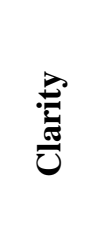 & 를 & 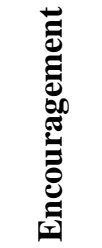 & 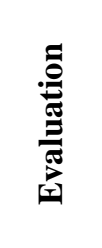 & & 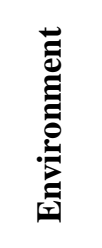 & 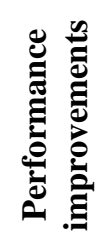 \\
\hline \multirow{2}{*}{ payment } & Correlation & 0.065 & 0.319 & 0.261 & 0.120 & 0.273 & 0.327 & 0.243 & 0.325 \\
\hline & Probability value & 0.453 & 0.000 & 0.002 & 0.163 & 0.001 & 0.000 & 0.004 & 0.000 \\
\hline \multirow{2}{*}{ promotion and progress } & Correlation & 0.101 & 0.300 & 0.198 & 0.202 & 0.297 & 0.286 & 0.235 & 0.311 \\
\hline & Probability value & 0.242 & 0.000 & 0.021 & 0.018 & 0.000 & 0.001 & 0.006 & 0.000 \\
\hline \multirow{2}{*}{ supervisor } & Correlation & 0.127 & 0.291 & 0.207 & 0.092 & 0.280 & 0.261 & 0.223 & 0.275 \\
\hline & Probability value & 0.142 & 0.001 & 0.016 & 0.287 & 0.001 & 0.002 & 0.009 & 0.001 \\
\hline \multirow{2}{*}{ nature of work } & Correlation & 0.186 & 0.363 & 0.280 & 0.218 & 0.328 & 0.198 & 0.236 & 0.338 \\
\hline & Probability value & 0.030 & 0.000 & 0.001 & 0.011 & 0.000 & 0.021 & 0.006 & 0.000 \\
\hline \multirow{2}{*}{ colleagues } & Correlation & 0.80 & 0.278 & 0.300 & 0.133 & 0.398 & 0.306 & 0.249 & 0.336 \\
\hline & Probability value & 0.335 & 0.001 & 0.000 & 0.122 & 0.000 & 0.000 & 0.004 & 0.000 \\
\hline \multirow{2}{*}{ job satisfaction } & Correlation & 0.143 & 0.369 & 0.292 & 0.171 & 0.360 & 0.323 & 0.282 & 0.372 \\
\hline & Probability value & 0.098 & 0.000 & 0.001 & 0.046 & 0.000 & 0.000 & 0.001 & 0.000 \\
\hline
\end{tabular}

The results showed that all the relationships had a positive direction and at the error level of 0.05 , the payment component has a meaningful relationship with all components of performance improvement, except for the ability and incentive. The relationship between promotion and progress with performance improvement was also significant but the relationship between promotion and progress will ability was not significant. Investigating the relationship between supervisors showed that this relationship was significant in all components except for the ability and incentive. The nature of work had a significant relationship with all the components of performance improvement and its overall state. Investigating the relationship between colleagues 
also showed that this relationship was significant in all components except for the ability and incentive. But overall staff satisfaction had a positive relationship with performance improvement and its components.

The main hypothesis: An evaluation model can be presented according to research conceptual model and based on factors affecting employee performance and satisfaction. To analyze the main hypothesis, LISREL software was used. After drawing the research analytical model based on data, the model of measurement was obtained by Lisrel software. A general model was obtained from micro data which significantly confirmed the path coefficients in it. The values of factor load showed a positive and significant relationship between satisfaction and performance. The results are presented in the chart below. In the study of this model, the ratio of the $\mathrm{k}$ square to the degree of freedom was 2.54 , the CFI index was 0.85 , the NFI index was 0.78 , the GFI was 0.46, the RMSEA error was 11 and the SRMR error was equal to 12.2 , which implied fitting the right model.

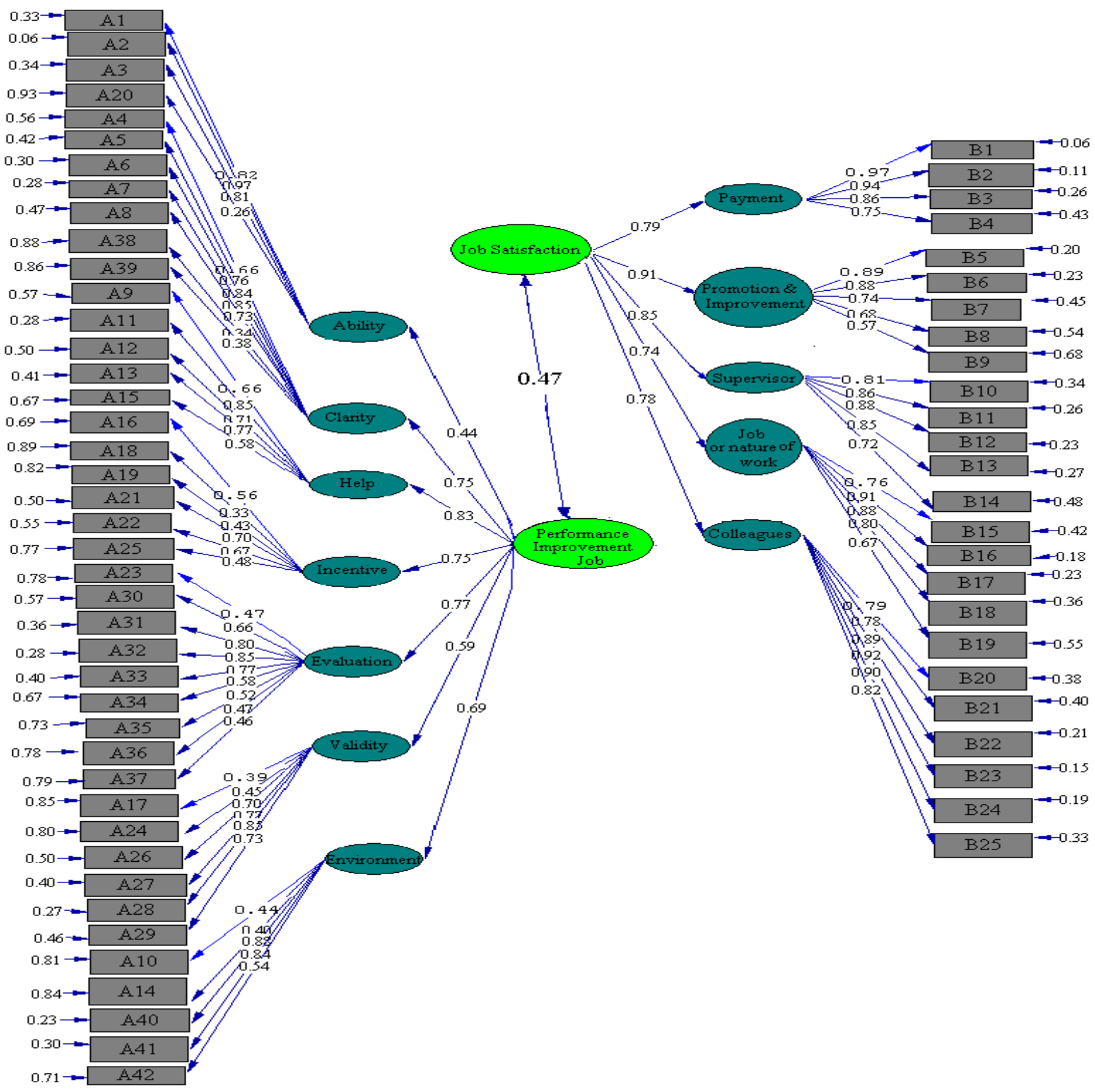

Figure 2. The values of the standard path coefficients in the overall research model. 
Since the significance level is zero (it is lower than 0.05), it can be concluded that despite the difference in the ranking average of the weaknesses in sport for all, this difference is not significant and the weaknesses have a similar impact on the sport for all policy-making process.

\section{DISCUSSION}

The results of the research hypothesis test regarding the status of improvement of performance and its components among employees of sports federations showed that the status of improvement of performance and all its components, except for the components of credit and environment, was in a favorable situation; therefore, the researcher hypothesis indicating favorable status of performance improvement was confirmed. In the research of Rahman et al. (2017), the role of the work environment was high (6). In some studies evaluation was criticized by staff and even managers for various reasons (1315). From the results of the research hypotheses in the study of the status of job satisfaction and its components among employees of sports federations, it was found that the job satisfaction status was lower than the mean in staff and Wilcoxon test was not meaningful, thus confirming the undesirable level of satisfaction. Also, in the components of payment, promotion and progress of dissatisfaction was observed and in the component of the supervisor, although the mean was greater than average, but was not statistically significant either. In the components of the nature of work and colleagues, the level of satisfaction was higher than mean and it can be assumed that the employees were only satisfied with these two components. Mossadegh Rad (2004) found the following in his research: (a) Staff showed lower job satisfaction in payment, benefits, working conditions, progress, and communication. (b) Staff showed more job satisfaction in factors such as nature of work, colleagues and supervisor (21). In a study by Memari et al. (2013), it was mentioned that one of the main tasks of the sports federations is assessment (22). The results of the hypothesis test indicate that there a relationship exists between job satisfaction and its components with performance improvement and its components.
Payment component had a meaningful relationship with all the components of performance improvement, except for the ability and incentive. The relationship between promotion and progress was also significant with performance improvement but the relationship between promotion and progress was not significant. It was shown that a significant relationship existed between supervisor and all components except for the ability and incentive. The nature of work also had a significant relationship with all the components of performance improvement as well as its overall state. Investigating the relationship between colleagues also showed that it had a meaningful relationship with all components except for the ability and incentive. Overall satisfaction of employees was also positively correlated with improving performance and its components. Ghamari and Pourfarzad (2010) suggested that evaluation has a positive effect on achievement of organizational goals (23). According to the findings from the main hypothesis of the research, it can be concluded that the conceptual model of research can be explained based on research data. The values of the factor load imply the fitness of the model. Its means: ability, clarity, assistance, incentive, evaluation, credibility, and environment are factors that affect the improvement of job performance while payment, promotion and progress, supervisor, job or the nature of work and colleagues are factors that affect job satisfaction. A two-way relationship also exists between job satisfaction and job performance. Finally, the proposed model of the research is confirmed as a model of job performance evaluation (Integrated SelfAssessment Model Based on Acu \& GDI Indicators). According to the findings of Soltani (2012), the growth and promotion, the nature of the job, and the incentive and motivation are factors affecting the performance of employees (24). According to Jamalzadeh et al. (2016), there is a direct relationship between job satisfaction of individuals and their performance, and those who are satisfied do their job better. When job satisfaction is created that employees feel, the content and field of work provides what is valuable to the employee; therefore, in order to 
increase job satisfaction, variables related to job satisfaction should be identified and strengthened and addressed to meet needs They should be taken into consideration at work (25). The findings of Bahrami et al. (2016) suggest that a two-way relationship exist between job satisfaction and performance improvement (5).

\section{CONCLUSION}

Emphasizing the importance of the evaluation system to improve employee's performance and satisfaction, and on the other hand, the role of these factors in creating a favorable atmosphere in sports organizations, the results of this research can affect the level of effort and future of employees, and in addition to showing strengths of the employees, it will direct managers to identify the weaknesses and resolve productivity issues, thereby giving employees adequate access, as well as reducing conflicts between supervisors and subordinates.

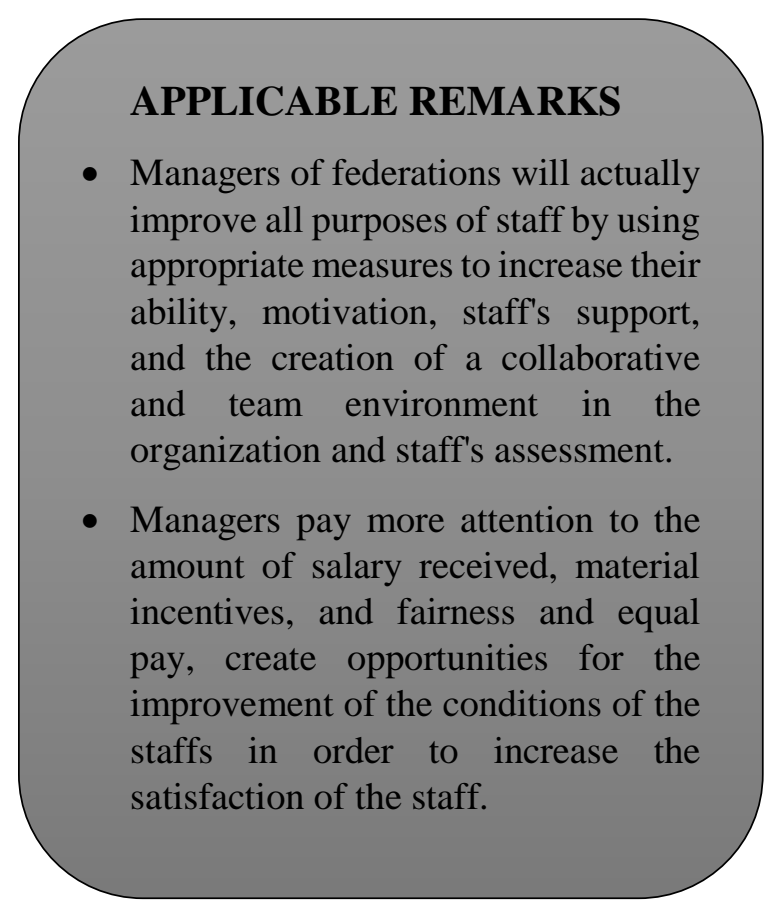

\section{REFERENCES}

1. Pradhan RK, Jena LK. Employee Performance at Workplace: Conceptual Model and Empirical Validation. Business Perspectives and Research. 2017;5(1):69-85.

2. Fogaça N, Rego MCB, Melo MCC, Armond LP, Coelho FA. Job Performance Analysis: Scientific Studies in the Main Journals of Management and Psychology from 2006 to 2015. International Society for Performance Improvement. 2018;30(4):231-47.

3. Ferdosi MH, Korayi A, Marashian FS. Designing and compiling a matching pattern in the work environment and the job performance of the employees of the General Department of Sports and Youth in Khuzestan province: the role of mediator of corporate civil behavior. Scientific Journal Of Organizational Behavior Management in Sport Studies. 2018;5(1):33-42 [Article in farsi].

4. Naghavi SA, Azar A, Asadi MM. Investigation of Spiritual Intelligence, Organizational Commitment and Job Satisfaction Employees of Sport and Youth General Office of Selected Provinces Scientific Journal Of Organizational Behavior Management in Sport Studies. 2016;3(3):75-86 [Article in Farsi].

5. Bahrami S, Zardoshtiyan S, Hosseini M. Impact of job satisfaction and organizational on citizenship behavior (individual and organizational) employees of the Ministry of Sport and Youth. Scientific Journal Of Organizational Behavior Management in Sport Studies. 2017;4(1):11-8 [Article in farsi].

6. Rahman K-U, Akhter W, Khan SU. Factors affecting employee job satisfaction: A comparative study of conventional and Islamic insurance. Cogent Business \& Management. 2017;4(1):1-15.

7. Jalili Shishvan A, Tabatabaei Adnan E, Jalili Shishvan F. Regressive Analysis of the Organizational Health Inventory and Job Satisfaction with Job Burnout of Physical Education Teachers in Tehran Province. Scientific Journal Of Organizational Behavior Management in Sport Studies. 2018;5(2):101-9 [Article in farsi].

8. Gul H, Usman M, Liu Y, Rehman Z, Jebran K. Does the effect of power distance moderate the relation between person environment fit and job satisfaction leading to job performance? Evidence from Afghanistan and Pakistan. Future Business Journal. 2018;4(1):68-83.

9. Raziq A, Maulabakhsh R. Impact of Working Environment on Job Satisfaction. Procedia Economics and Finance. 2015;23:717-25.

10. Suttikun C, Chang HJ, Bicksler H. A qualitative exploration of day spa therapists' work motivations and job satisfaction. Journal of Hospitality and Tourism Management. 2018;34:1-10.

11. Niazi Tabar M, Hamidi M, Hoseini SE. The Relationship of Motivation-hygiene Factors and Job Involvement in Employees of National Olympic Committee of Iran. Sport Management Studies. 2013;5(19):51-62 [Article in Farsi]. 
12. Keshavarz L. Identify factors affecting the behavior of managers in assessing sport facilities. Scientific Journal Of Organizational Behavior Management in Sport Studies. 2017;4(2):29-39 [Article in farsi].

13. Skandari Dastgiri S, Amirtash AM, Safania AM. The Relationship between the Performance Components Evaluation in the Efficiency of Sport Federations. Scientific Journal Management System. 2018;6(24):19-26 [Article in Farsi].

14. Asadi H, Ghanbarpoor A, Ghorbani MH, Doosti M. The Relationship between Organizational Learning and Performance among Experts of Physical Education Organization of Islamic Republic of Iran. Journal of Sport Management. 2009;1(1):237-47 [Article in farsi].

15. Mrhálek T, Kajanová A. Work satisfaction and mental pressure of social workers and workers in social services. Kontakt. 2018;20(2):e166-e70.

16. Huselid MA. The Impact Of Human Resource Management Practices On Turnover, Productivity, And Corporate Financial Performance. Academy of Management Journal. 1995;38(3):635-72.

17. Chandra A, Frank ZD. Utilization of Performance Appraisal Systems in Health Care Organizations and Improvement Strategies for Supervisors. The Health Care Manager. 2004;23(1):25-30.

18. Javaherizadeh N, Mehrabi J, Bazvand F. Comparison of the Results of Performance Appraisal Using Traditional Method and 360-Degree Feedback: The Relationship with Employee Satisfaction in Lorestan University of Medical Sciences. Journal of Development \& Evolution Mnagement. 2011;1390(6):57-68 [Article in farsi].

19. Ansari M, Rahmany Youshanlouei H, Mahmoud Danialei Dehhoz M, Mardani A. A Survey of the Affection of Financial and non Financial Factors in Performance Assessment of Job Satisfaction in the View Point of Personnel of Accepted Companies in the Iranian Stock Exchange Journal of Accounting and Auditing Review. 2011;18(63):120 [Article in farsi].

20. Nezad Sajjadi SA, Soleimani Damaneh J. Identify and Prioritize the Criteria of Performance Evaluation of Iranian Sport Federation Form Expert Point of View Sing the AHP Model. Sport Management Studies. 2014;6(23):17992 [Article in farsi].

21. Mosadeghrad AM, Ferlie E, Rosenberg D. A study of the relationship between job satisfaction, organizational commitment and turnover intention among hospital employees. Health Services Management Research. 2008;21(4):211-27.

22. Memari Z, Hamidi M, Asghari Jafarabadi M. Exploratory Study of Iranian Elite Sport Coach Evaluation Criteria. Sport Management Studies. 2013;5(20):97-126 [Article in farsi].

23. Ghamari Zare Z, Purfarzad Z, Anoosheh M, Seraji A, Ghorbani M. The correlation between quality of performance appraisal and job satisfaction of nurses. Quarterly Journal of Nersing Management. 2013;1(4):18-27 [Article in farsi].

24. Soltani HA, Parsa Nasab M, Rashidi MM. Surveying the Assessment System of the Performance and Effect of the Motivational-cultural Factors on the Improvement of Personnel Performance (case study: Iran's District 12 Grain Company). Scientific Journal Management System. 2013;7(26):147-74 [Article in Farsi].

25. Jamalzadeh M, Javadipour M, Khosro Babadi AA. The Relationship between Organizational Health and Job Satisfaction of Physical Education Teachers in Junior High Schools of Tehran. Sport Management Studies. 2018;9(46):17-30 [Article in farsi]. 